\title{
Gamma-Ray Susceptibility of Immature and Mature Hippocampal Cultured Cells
}

\author{
Myoung-Sub SONG ${ }^{1) * *}$, Joong-Sun $\mathrm{KIM}^{1) * *}$, Miyoung YANG ${ }^{1)}$, Sung-Ho $\mathrm{KIM}^{1)}$, Jong-Choon $\mathrm{KIM}^{1)}$, Soo Hyun PARK ${ }^{1)}$, \\ Taekyun $\mathrm{SHIN}^{2)}$ and Changjong $\mathrm{MOON}^{1) *}$ \\ ${ }^{1)}$ College of Veterinary Medicine and Animal Medical Institute, Chonnam National University, Gwangju 500-757 and \\ ${ }^{2)}$ College of Veterinary Medicine and Applied Radiological Science Research Institute, Jeju National University, Jeju 690-756, South Korea
}

(Received 9 December 2009/Accepted 12 January 2010/Published online in J-STAGE 26 January 2010)

ABSTRACT. Ionizing radiation suppresses neurogenesis in the mammalian brain. This in vitro study compared the detrimental effect of acute gamma-irradiation on immature hippocampal cells with mature cells. Both rat immature (0.5 day in vitro (DIV)) and mature hippocampal cells (14 DIV) were irradiated with 0-4 Gy gamma-rays. Cell viability was analyzed by using a 3-[4,5-dimethylthiazol-2-yl]2,5-diphenyl tetrazolium bromide (MTT) assay. DNA fragmentation study was performed by extracting intracellular DNA. Morphological features of apoptosis were characterized by 4',6-diamidine-2'-phenylindole, dihydrochloride (DAPI) staining. MTT assay revealed that the survival rate of immature hippocampal cells declined in a dose-dependent manner within the range of irradiation applied, but was not changed in mature cells. Intranucleosomal DNA fragmentation in a ladder like pattern was dose-dependently increased in immature cells, but not in mature cells. The number of apoptotic nuclei in immature cells increased significantly in a dose-dependent manner within the range of irradiation applied. Active caspase- 3 and cleaved poly (ADP-ribose) polymerase (PARP) expressions in immature hippocampal cells at $6 \mathrm{hr}$ after 2 Gy exposure were markedly higher than control levels. The significantly greater radiosensitivity of immature hippocampal cells than that of the mature cells, indicates that the susceptibility of such hippocampal cells depends on their maturation. In addition, gamma-irradiation may induce caspase-dependent apoptosis in immature hippocampal cells. KEY WORDS: apoptosis, cell viability, gamma-ray, hippocampal cell, radiosensitivity.

J. Vet. Med. Sci. 72(5): 605-609, 2010

Ionizing radiation is one of the most effective therapies for treatment of tumors in the central nervous system (CNS). Although it is effective in treating malignancies, application of radiotherapy is limited due to potential damage of normal CNS tissue [11]. Irradiation has a variety of effects on both the developing and adult brain, even though the adult brain is less severe morphological changes to irradiation than other organs. Especially, under very low doses of radiation, the developing brain is one of the most radiosensitive organs $[9,7,16]$. Even very low doses of irradiation to the brain of an infant below 18-months-of-age can affect the patient's cognitive abilities in adulthood [6].

Exposure of mammalian brains to ionizing radiation induces apoptosis of neural immature progenitor cells in the subventricular zone of the lateral ventricles and in the subgranular zone of the hippocampal dentate gyrus $[3,4,10,12$, 17]. The phenomenon in adult mouse hippocampus may lead to hippocampal-dependent learning and memory impairment [10], although there is no radiation-induced apoptotic appearance in other hippocampal regions, including cornu ammonis (CA) 1 and CA3. Therefore, it is important to clarify the degree of radiosensitivity in the stages of neural development at which they are most vulnerable.

In addition, studies of radiation-induced effects on cognitive function related to adult hippocampus are very difficult because they rely on complicated in vivo models [2]. How-

\footnotetext{
* Correspondence to: Dr. Moon, C., Department of Veterinary Anatomy, College of Veterinary Medicine, Chonnam National University, Gwangju 500-757, South Korea.

e-mail: moonc@chonnam.ac.kr

**The frst two authors equally contributed to this study.
}

ever, it may possible to address specific mechanisms associated with radiation effects on neural immature and mature hippocampal cells by using in vitro approaches. Thus, an in vitro system needs to be established to screen radioprotectants and study various brain perturbation factors caused by radiation exposure.

This study compared the detrimental effect of acute gamma-irradiation on 0.5 day in vitro (DIV) immature hippocampal cells with that on the 14 DIV mature cells to elucidate the differential effect of ionizing radiation on immature and mature hippocampal cells in an in vitro system.

\section{MATERIALS AND METHODS}

Primary hippocampal cell culture: Pregnant SpragueDawley rats were obtained from a specific pathogen-free colony at Oriental Inc. (Seoul, Korea). Hippocampi were dissected from postnatal day 0 rats, and prepared for culturing. After dissection, tissues were chopped into $1 \mathrm{~mm}^{3}$ dices, and digested with 10 units $/ \mathrm{m} l$ papain (Worthington, Freehold, NJ, U.S.A.) and 100 units $/ \mathrm{m} l$ DNase I (Roche, Basel, Switzerland) in dissociation buffer (82 $\mathrm{mM} \mathrm{Na}_{2} \mathrm{SO}_{4}$, $30 \mathrm{mM} \mathrm{K}_{2} \mathrm{SO}_{4}, 5.8 \mathrm{mM} \mathrm{MgCl}_{2}, 0.25 \mathrm{mM} \mathrm{CaCl}_{2}, 20 \mathrm{mM}$ glucose, $0.001 \%$ phenol red, $0.45 \mathrm{mg} / \mathrm{m} l$ cysteine, and 1.5 mM 4-(2-hydroxyethyl)-1-piperazineethanesulfonic acid, $\mathrm{pH} 7.6)$ at $37^{\circ} \mathrm{C}$ for $30 \mathrm{~min}$. The digestion was washed with dissociation buffer and triturated with Neurobasal A medium (Invitrogen, Carlsbad, CA, U.S.A.). The cells were seeded at a density of $0.4 \times 10^{6}$ cells/well and $2 \times 10^{6}$ cells/ dish on poly-D-lysine hydrobromide $(150 \mu \mathrm{g} / \mathrm{ml}$; Sigma- 
Aldrich, St. Louis, MO, U.S.A.) coated 4-well plates and 35 mm dishes (NUNC ${ }^{\mathrm{TM}}$; Thermo Fisher Scientific, Pittsburgh, PA, U.S.A.), respectively. Two hours after plating, Neurobasal A was replaced with growth media including Neurobasal A, $1 \times$ B27 supplement (Invitrogen), 100 units $/ \mathrm{m} l$ penicillin, $0.1 \mathrm{mg} / \mathrm{m} l$ streptomycin, and $0.5 \mathrm{mM}$ glutamine and all cultures were kept at $37^{\circ} \mathrm{C}, 5 \% \mathrm{CO}_{2}$.

Culture irradiation: Cells at 0.5 and 14 DIV were irradiated with $0,0.5,2$, or $4 \mathrm{~Gy}$ of ${ }^{137} \mathrm{CS}$-generated gamma rays using a Gamma-cell Elan 3000 (Nordion International, Kanata, ON, Canada). The mean dose rate of the gammarays was $3.1 \mathrm{~Gy} / \mathrm{min}$. The irradiation doses were measured at the cultured plate exposure position with an IC-17 ionization chamber (Far West Technology, Goleta, CA, U.S.A.) and an RDM 2A electrometer (Therados-Scanditronix, Uppsala, Sweden). Control samples were sham-irradiated with 0 Gy. The cells were assayed at $6,12,24$ and $48 \mathrm{hr}$ postirradiation (pi.).

Cell viability evaluation: Cell viability was evaluated by using 3-[4,5-dimethylthiazol-2-yl]-2,5-diphenyl tetrazolium bromide (MTT) assay. The assay was based on the reduction of MTT by living cells to yield a soluble formazan product that could be detected colorimetrically. MTT was added to cells in 4-well plates (NUNC ${ }^{\mathrm{TM}}$; Thermo Fisher Scientific) to $0.5 \mathrm{mg} / \mathrm{m} l$ in culture medium without phenol red and serum. After $2 \mathrm{hr}$ incubation at $37^{\circ} \mathrm{C}$ with $5 \% \mathrm{CO}_{2}$, the resulting formazan crystals were dissolved in MTT solubilization solution (Sigma-Aldrich). The solublized formazan products were quantified by an Emax spectrophotometer (Molecular Devices, Sunnyvale, CA, U.S.A.) for absorbance at a wavelength of $570 \mathrm{~nm}$. The background absorbance was subtracted by spectrophotometric measurements at a wavelength of $690 \mathrm{~nm}$.

DNA fragmentation analysis: For the DNA analysis, $2 \times$ $10^{6}$ control cells/dish and the irradiated ones with $0-4$ Gy were collected at $12 \mathrm{hr}$ pi. The cells were scraped and collected by centrifugation, washed with phosphate buffered saline (PBS) and resuspended in lysis buffer (1\% sodium dodecyl sulfate (SDS), $0.2 \mathrm{mg} / \mathrm{m} l$ proteinase $\mathrm{K}, 100 \mathrm{mM}$ $\mathrm{NaCl}, 20 \mathrm{mM}$ Tris-HCl, $\mathrm{pH} \mathrm{8.0)}$ and incubated for $4 \mathrm{hr}$ at $37^{\circ} \mathrm{C}$. Cells were centrifugated at $16,000 \times \mathrm{g}$ for $15 \mathrm{~min}$ at $4^{\circ} \mathrm{C}$ to separate the fragmented DNA (supernatant) from intact chromatin DNA (pellet). Supernatant DNA was extracted with an established phenol/chloroform/isoamylalcohol method. Ten microliters of extracted DNA, was used for $1.2 \%$ agarose electrophoresis.

4',6-Diamidine-2'-phenylindole, dihydrochloride (DAPI) staining for counting of apoptotic cells: Morphological features of apoptosis were characterized by condensed and fragmented nuclei after staining with DAPI (Thermo Fisher Scientific). Cell cultures were fixed with $4 \%$ paraformaldehyde (Sigma-Aldrich) in PBS for $20 \mathrm{~min}$ at room temperature (RT). After three PBS washes, $1 \mu \mathrm{g} / \mathrm{m} l$ DAPI in PBS was added and the cells were incubated at RT for $5 \mathrm{~min}$. After two washes, the number of stained nuclei with apoptotic morphology was determined with a ProgRes ${ }^{\circledR}$ CFscan fluorescence digital camera (Jenoptik, Jena, Germany) and enumerated using ProgRes ${ }^{\circledR}$ CapturePro 2.5 software (Jenoptik) in four random fields of quadruplicate samples at $400 \times$ magnifications.

Western blotting: Medium was removed and a SDS sample buffer $(4 \times)$ was added to each culture. The cells scraped and sonicated for $10 \mathrm{sec}$. The samples were heated to $100^{\circ} \mathrm{C}$ for $10 \mathrm{~min}$. The samples were then separated by $10 \%$ SDSpolyacrylamide gel electrophoresis (PAGE), transferred to a nitrocellulose membrane, and blocked with 1\% normal goat serum and $0.5 \%$ bovine serum albumin in PBS-T (PBS, $0.1 \%$ tween 20 ) for $30 \mathrm{~min}$ at RT. The membranes were then incubated with a 1: 1,000 dilution of either rabbit anticleaved (active) caspase-3 antibody (Cell Signaling Technology, Beverly, MA, U.S.A.) or rabbit anti-poly (ADPribose) polymerase (PARP) antibody (Cell Signaling Technology) in PBS-T overnight at $4^{\circ} \mathrm{C}$. After extensive washing and incubation with a 1:10,000 dilution of horseradish peroxidase (HRP)-conjugated goat anti-rabbit IgG (Vector Laboratories, Burlingame, CA, U.S.A.) for $1.5 \mathrm{hr}$ at RT, the signals were visualized using chemiluminescence methods
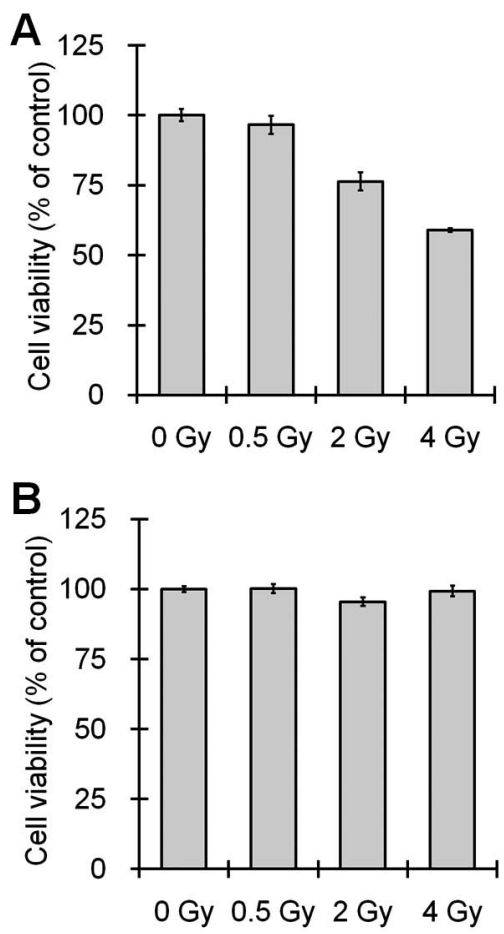

Fig. 1. Gamma-ray decline in cell viability in immature hippocampal cells. MTT assay showing cytotoxicity of hippocampal cells induced by gamma irradiation at 0.5 (A) and 14 DIV (B). MTT was added to each well $12 \mathrm{hr}$ after irradiation, and absorbance was measured using a microplate reader. At $0.5 \mathrm{DIV}$, the cell viability significantly declined in dose-dependent manner within the range of irradiation applied (0-4 Gy). In contrast, at 14 DIV, cell viability was not changed. The data represent the mean \pm $\mathrm{SE}, \mathrm{n}=8$ cultures per condition. 

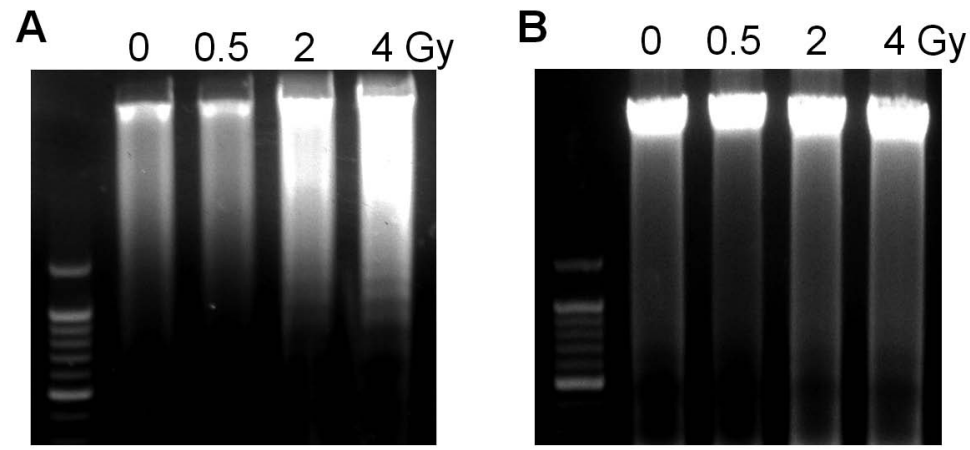

Fig. 2. Gamma-ray induces DNA fragmentation in immature hippocampal cells. Intranucleosomal DNA fragmentation indicated by a ladder like pattern was dose-dependently increased $12 \mathrm{hr}$ after irradiation at 0.5 DIV (A). However, the mature cells (B) did not show the DNA fragmentation after irradiation at 14 DIV.

(SuperSignal ${ }^{\circledR}$ West Pico; Thermo Fisher Scientific). For normalization purposes, the membranes were reprobed with a 1:20,000 dilution of beta-actin antibody (Sigma-Aldrich). Several exposure times were used to obtain the signals in the linear range. The bands were quantified using Scion Image Beta 4.0.2 for Windows XP software (Scion, Frederick, ME, U.S.A.).

Statistical analysis: The data is reported as the mean \pm SE. The data was analyzed using one-way analysis of variance (ANOVA) followed by a Student-Newman-Keuls post hoc test for multiple comparisons. In all cases, a $p$ value $<0.05$ was considered significant.

\section{RESULTS}

Effect of gamma-ray on viability of hippocampal cells: We first analyzed the cell viability of cultured hippocampal cells induced $12 \mathrm{hr}$ after irradiation of $0-4$ Gy by the MTT assay and determined whether there was a difference of cell viability between 0.5 DIV immature and 14 DIV mature cells. At $0.5 \mathrm{DIV}$, cell viability decreased in a dose-dependent pattern within the range of irradiation applied (0-4 Gy) (Fig. 1A). At 14 DIV, however, irradiation did not decrease cell viability (Fig. 1B).

DNA fragmentation in cultured hippocampal cells with gamma-ray exposure: Neural DNA was isolated and subjected to conventional electrophoresis. At $0.5 \mathrm{DIV}$, a clear ladder-like pattern in the DNA from the irradiated hippocampal cells indicated that radiation induced internucleosomal DNA fragmentation, a common characteristic of apoptosis. The DNA laddering obviously increased $12 \mathrm{hr}$ after irradiation with increasing irradiation dose (Fig. 2A), whereas it was hardly detected in irradiated cells at $14 \mathrm{DIV}$ (Fig. 2B).

Morphological appearance of apoptosis in immature hippocampal cells with gamma-ray exposure: Differential interference contrast images showed that cellular shrinkage and loss in irradiated cells (Fig. 3C) was increased compared with sham-irradiated controls at 0.5 DIV (Fig. 3A).
DAPI fluorescence images also showed that nuclear pyknosis increased $12 \mathrm{hr}$ after irradiation (Fig. 3D), compared with sham-irradiated controls (Fig. 3B). At 14 DIV, however, irradiation did not increase cellular shrinkage and nuclear pyknosis (data not shown). To characterize the time- and dose-dependent changes of the apoptotic response in 0.5 DIV cells, nuclear pyknotic cells were scored 6, 12, 24 or $48 \mathrm{hr}$ after $0-4$ Gy irradiation. As shown in Fig. 3E, there was an increase in apoptotic cells as early as $6 \mathrm{hr}$ after irradiation, with the peak incidence occurring at 12 and 24 $\mathrm{hr}$, but at $48 \mathrm{hr}$ the fraction of cells displaying nuclear fragmentation had diminished.

Active caspase-3 and cleaved PARP are significantly increased by gamma-ray exposure: To determine whether radiation-induced apoptosis in immature hippocampal cells was associated with the caspase-dependent pathway, caspase- 3 activation and caspase-specific PARP cleavage were assessed by Western blot (Fig. 4). At 0.5 DIV, active caspase- 3 and cleaved PARP expressions were significantly increased $6 \mathrm{hr}$ after 2 Gy irradiation, compared to sham-irradiated control levels (active caspase-3: relative optical density (OD), $10.86 \pm 1.1$-fold increase, $p<0.001$; cleaved PARP: relative OD $15.45 \pm 1.94$-fold increase, $p<0.001$ ).

\section{DISCUSSION}

In this study, viability of immature hippocampal cells, but not mature cells, significantly declined upon exposure of gamma-rays, indicating that neuronal resistance to gammairradiation was associated with neuronal differentiation. In addition, gamma-irradiation induced apoptosis in immature hippocampal cells through the caspase-dependent pathway.

In this report, we examined the gamma-irradiation susceptibility of hippocampal neurogenesis using 0.5 DIV hippocampal cells and 14 DIV mature hippocampal cells. Exposure of mammalian brains to ionizing radiation induces apoptosis of neural immature progenitor cells in vivo [3, 4]. Cultured hippocampal cells form functional synapses and a network after 3-5 DIV [21]. Therefore, we chose to apply 


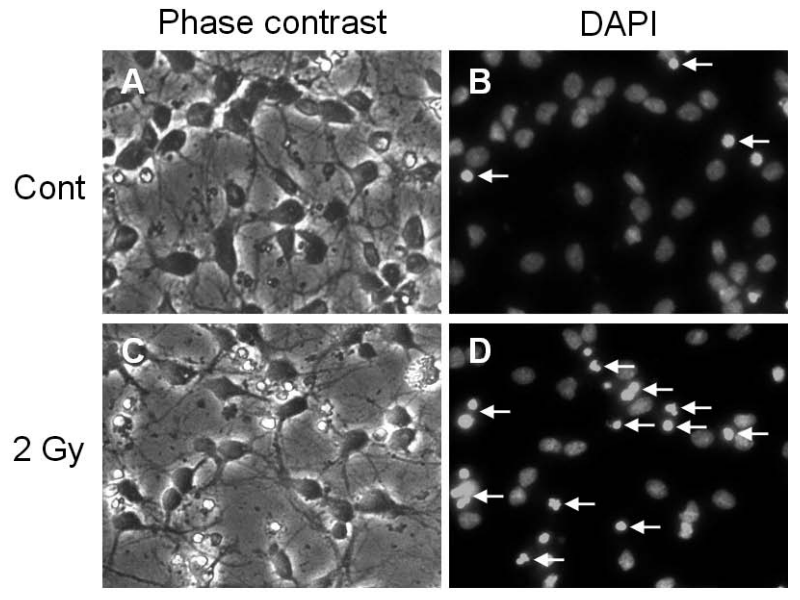

E

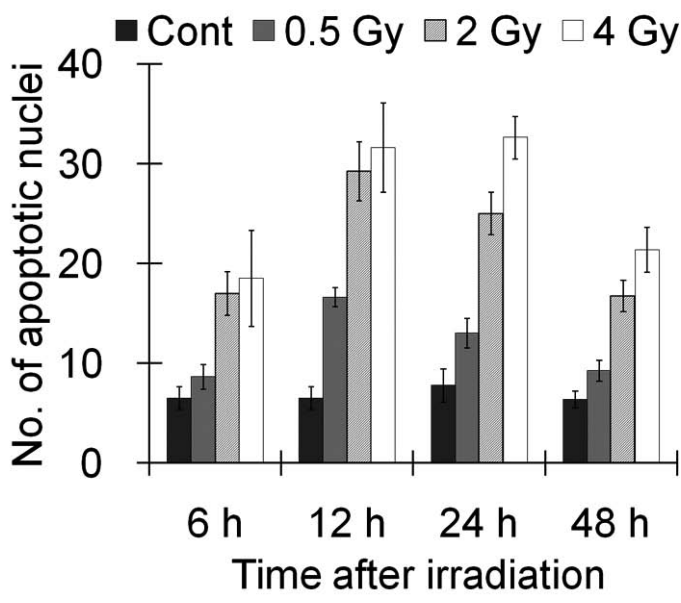

Fig. 3. DAPI staining showing time- and dose-dependent apoptotic changes in immature hippocampal cells. (A-D) Apoptotic cells with condensed and fragmented nuclei were observed in immature hippocampal cells after acute gamma irradiation (a single dose of 2 Gy) at 0.5 DIV. Arrows indicate cells with apoptotic nuclei (B and D). (E) The number of apoptotic nuclei began to increase significantly $6 \mathrm{hr}$ pi., reaching their highest level at $12 \mathrm{hr}$ and $24 \mathrm{hr}$, respectively, and then subsequently declining at $48 \mathrm{hr}$ pi. The data represents the mean $\pm \mathrm{SE}, \mathrm{n}=4$ cultures per condition.

gamma-irradiation to 0.5 DIV-cultured hippocampal cells, which are comparable to neural immature progenitor cells before cell connection and synapse formation.

Many neuropathological conditions in CNS are characterized by neuronal apoptosis [1]. Exposure of the CNS to ionizing radiation induces neuronal apoptosis via DNA damage and oxidative stress [5]. The consensus view holds that noncycling cells such as neurons are more resistant to irradiation than cycling cells including astrocytes and vascular endothelial cells. However, an irradiation study using developing rat brains suggested that the radiosensitive population consists primarily of cells nearing cell division or cells that have recently completed mitosis and are beginning
A
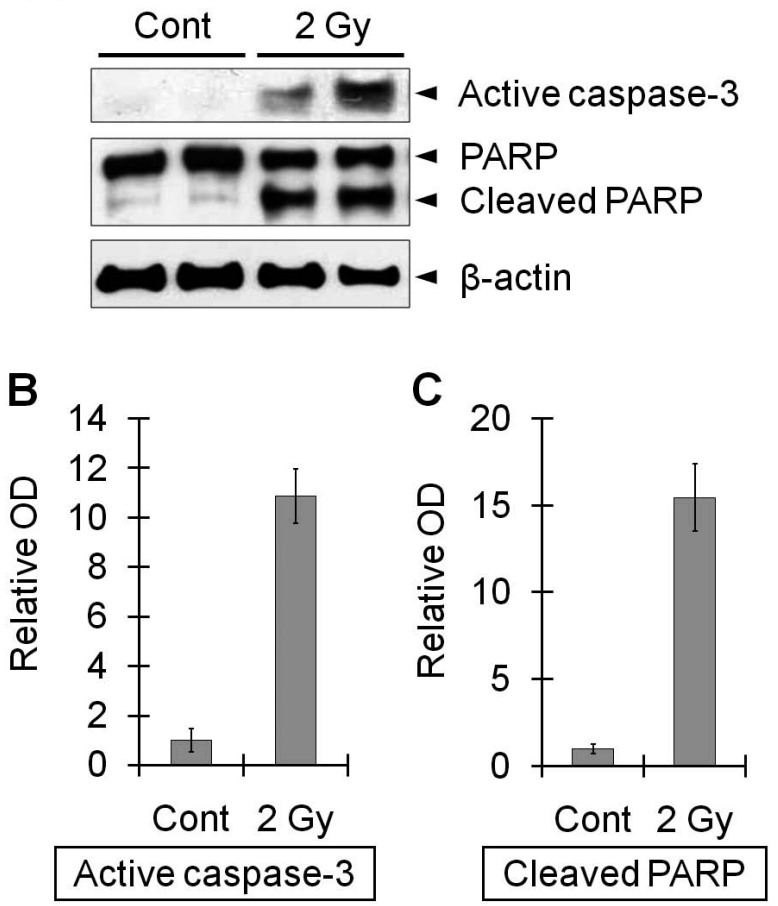

Fig. 4. Western blot analysis showing active caspase-3 and cleaved PARP expression in immature hippocampal cells. (A) Representative immunoblots for detection of active caspase-3 (17 kDa), PARP (118 kDa) and cleaved PARP (89 kDa) at $6 \mathrm{hr}$ after sham-irradiation and 2 Gy irradiation at 0.5 DIV hippocampal cell cultures. (B and C) The relative expression levels of active caspase-3 (B) and cleaved PARP (C) were determined by densitometric data analysis and normalized to the beta-actin signal from three different samples. The data represents the mean $\pm \mathrm{SE}, \mathrm{n}=3$ cultures per condition.

to differentiate [8]. A previous in vitro study showed that non-cycling postmitotic neurons retain their susceptibility to $\mathrm{X}$-irradiation [5]. Recently, 7 DIV neurons were reported as being susceptible to X-irradiation at a high dose (30 Gy), while 21 DIV neurons were resistant to this irradiation [18]. Gobbel et al. [5] reported that 2 Gy X-irradiation is the threshold irradiation dose at 7 DIV. Furthermore, X-irradiation of immature neurons causes structural deficits (i.e., a loss of cell connection and reduction in the level of synapse formation) in the surviving neurons, which are thought to result in their dysfunction [14]. In this study, cell viability declined in a dose-dependent manner within the relative low-range of irradiation applied (0-4 Gy) at 0.5 DIV. Therefore, 0.5 DIV hippocampal cells are susceptible to irradiation of relative low doses ( $0-4$ Gy), but 14 DIV hippocampal cells were resistant to this irradiation.

Additionally, cultures of 0.5 DIV hippocampal cells provide a useful tool for the analysis of critical mechanistic parameters associated with radiation response of the brain and to better understand the molecular changes in radiationinduced apoptosis of neural cells. During the caspase- 
dependent apoptotic process, PARP is proteolytically cleaved and inactivated by caspase-3, a process that is widely used as an apoptotic marker [15]. Intriguingly, PARP is a 'death substrate' of caspase-3 [13, 20], and the cleavage of PARP abolishes its enzymatic activity and saves $\mathrm{NAD}^{+}$and ATP, which drives the cell to apoptosis [19]. In this study, active caspase- 3 and cleaved PARP expressions were significantly increased after exposure of 2 Gy gammarays, suggesting that radiation-induced apoptosis in immature hippocampal cells depends on pro-apoptotic caspase pathway.

In summary, this in vitro study has confirmed that the radiosensitivity of immature hippocampal cells is significantly higher than that of the mature cells, indicating that the susceptibility of such hippocampal cells depends on their differentiation. In addition, this study has established a beneficial in vitro system for screening drugs and studying various brain perturbation factors on related functions.

ACKNOWLEDGMENTS. This work was supported by the Korea Science and Engineering Foundation (KOSEF) grant funded by the Korea government (MEST) and by the Grant of the Korean Ministry of Education, Science and Technology (The Regional Core Research Program/Biohousing Research Institute). This work was supported by the Biohousing Research Center.

\section{REFERENCES}

1. Culmsee, C., Bondada, S. and Mattson, M. P. 2001. Hippocampal neurons of mice deficient in DNA-dependent protein kinase exhibit increased vulnerability to DNA damage, oxidative stress and excitotoxicity. Brain Res. Mol. Brain Res. 87: 257-262.

2. Fike, J. R., Rosi, S. and Limoli, C. L. 2009. Neural precursor cells and central nervous system radiation sensitivity. Semin. Radiat. Oncol. 19: 122-132.

3. Fukuda, A., Fukuda, H., Swanpalmer, J., Hertzman, S., Lannering, B., Marky, I., Björk-Eriksson, T. and Blomgren, K. 2005. Age-dependent sensitivity of the developing brain to irradiation is correlated with the number and vulnerability of progenitor cells. J. Neurochem. 92: 569-584.

4. Fukuda, H., Fukuda, A., Zhu, C., Korhonen, L., Swanpalmer, J., Hertzman, S., Leist, M., Lannering, B., Lindholm, D., BjörkEriksson, T., Marky, I. and Blomgren, K. 2004. Irradiationinduced progenitor cell death in the developing brain is resistant to erythropoietin treatment and caspase inhibition. Cell Death Differ. 11: 1166-1178.

5. Gobbel, G. T., Bellinzona, M., Vogt, A. R., Gupta, N., Fike, J. R. and Chan, P. H. 1998. Response of postmitotic neurons to X-irradiation: implications for the role of DNA damage in neuronal apoptosis. J. Neurosci. 18: 147-155.

6. Hall, P., Adami, H. O., Trichopoulos, D., Pedersen, N. L., Lagiou, P., Ekbom, A., Ingvar, M., Lundell, M. and Granath, F. 2004. Effect of low doses of ionising radiation in infancy on cognitive function in adulthood: Swedish population based cohort study. BMJ 328: 19.

7. Hays, S. R., Li, X. and Kimler, B. F. 1993. Is there an adaptive response to radiation in the developing brain of the fetal rat? Radiat. Res. 136: 293-296.

8. Hicks, S. P., D’Amato, C. J., Coy, M. A., O’Brien, E. D. and
Thruston, J. M. 1961. Migrating cells in the developing nervous system studied by their radiosensitivity and tritiated thymidine uptake. pp. 246-261. Brookhaven Symposium on Biology. In: (Joftes D.L. ed.), New York: Upton.

9. Johnson, D. L., McCabe, M. A., Nicholson, H. S., Joseph, A. L., Getson, P. R., Byrne, J., Brasseux, C., Packer, R. J. and Reaman, G. 1994. Quality of long-term survival in young children with medulloblastoma. J. Neurosurg. 80: 1004-1010.

10. Kim, J. S., Lee, H. J., Kim, J. C., Kang, S. S., Bae, C. S., Shin, T., Jin, J. K., Kim, S. H., Wang, H. and Moon, C. 2008. Transient impairment of hippocampus-dependent learning and memory in relatively low-dose of acute radiation syndrome is associated with inhibition of hippocampal neurogenesis. J. Radiat. Res. 49: 517-526.

11. Moore, A. H., Olschowka, J. A., Williams, J. P., Paige, S. L. and O'Banion, M. K. 2004. Radiation-induced edema is dependent on cyclooxygenase 2 activity in mouse brain. Radiat. Res. 161: 153-160.

12. Nakaya, K., Hasegawa, T., Flickinger, J. C., Kondziolka, D. S., Fellows-Mayle, W. and Gobbel, G. T. 2005. Sensitivity to radiation-induced apoptosis and neuron loss declines rapidly in the postnatal mouse neocortex. Int. J. Radiat. Biol. 81: 545-554.

13. Nicholson, D. W., Ali, A., Thornberry, N. A., Vaillancourt, A. P., Ding, C. K., Gallant, M., Gareau, Y., Griffin, P. R., Labelle, M., Lazebnik, Y. A., Munday, N. A., Raju, S. M., Smulson, M. E., Yamin, T., Yu, V. L. and Miller, D. K. 1995. Identification and inhibition of the ICE/CED-3 protease necessory for mammalian apoptosis. Nature 376: 37-43.

14. Okamoto, M., Suzuki, Y., Shirai, K., Mizui, T., Yoshida, Y., Noda, S., Al-Jahdari, W. S., Shirao, T. and Nakano, T. 2009. Effect of radiation on the development of immature hippocampal neurons in vitro. Radiat. Res. 172: 718-724.

15. Oliver, F. J., de la Rubia, G., Rolli, V., Ruiz-Puiz, M. C., de Murcia, G. and Murcia, J. M. 1998. Importance of poly(ADP-ribose) polymerase and its cleavage in apoptosis. Lesion from an uncleavable mutant. J. Biol. Chem. 273: 33533-33539.

16. Packer, R. J., Sutton, L. N., Atkins, T. E., Radcliffe, J., Bunin, G. R., D'Angio, G., Siegel, K. R. and Schut, L. 1989. A prospective study of cognitive function in children receiving whole-brain radiotherapy and chemotherapy: 2-year results. J. Neurosurg. 70: 707-713

17. Raber, J., Rola, R., LeFevour, A., Morhardt, D., Curley, J., Mizumatsu, S., VandenBerg, S. R. and Fike, J. R. 2004. Radiation-induced cognitive impairments are associated with changes in indicators of hippocampal neurogenesis. Radiat. Res. 162: $39-47$.

18. Shirai, K., Mizui, T., Suzuki, Y., Kobayashi, Y., Nakano, T. and Shirao, T. 2006. Differential effects of $\mathrm{x}$-irradiation on immature and mature hippocampal neurons in vitro. Neurosci. Lett. 399: $57-60$.

19. Simbulan-Rosenthal, C. M., Rosenthal, D. S., Iyer, S., Boulares, A. H. and Smulson, M. E. 1998. Transient poly(ADP-ribosyl)ation of nuclear protein and role of poly (ADP-ribose) polymerase in the early stages of apoptosis. J. Biol. Chem. 273: 13703-13712.

20. Tewari, M., Quan, L. T., O’Rourke, K., Desnoyers, S., Zeng, Z., Beidler, D. R., Poirier, G. G., Salvesen, G. S. and Dixit, V. M. 1995. Yama/CPP32 beta, a mammalian homolog of CED-3, is a CrmA-inhibitable protease that cleaves the death substrate poly (ADP-ribose) polymerase. Cell 81: 801-809.

21. Verderio, C., Coco, S., Pravettoni, E., Bacci, A. and Matteoli, M. 1999. Synaptogenesis in hippocampal cultures. Cell. Mol. Life Sci. 55: $1448-1462$. 